\title{
Development, Culture, and the Units of Inheritance
}

\author{
James Griesemer†ः \\ University of California, Davis
}

\begin{abstract}
Developmental systems theory (DST) expands the unit of replication from genes to whole systems of developmental resources, which DST interprets in terms of cycling developmental processes. Expansion seems required by DST's argument against privileging genes in evolutionary and developmental explanations of organic traits. DST and the expanded replicator brook no distinction between biological and cultural evolution. However, by endorsing a single expanded unit of inheritance and leaving the classical molecular notion of gene intact, DST achieves only a nominal reunification of heredity and development. I argue that an alternative conceptualization of inheritance denies the classical opposition of genetics and development while avoiding the singularity inherent in the replicator concept. It also yields a new unit-the reproducerwhich genuinely integrates genetic and developmental perspectives. The reproducer concept articulates the non-separability of "genetic" and "developmental" roles in units of heredity, development, and evolution. DST reformulated in terms of reproducers rather than replicators preserves an empirically interesting distinction between cultural and biological evolution.
\end{abstract}

1. Introduction. Theoretical perspectives in science coordinate models and phenomena. Coordination is necessary because phenomena are complex,

$\dagger$ Send requests for reprints to the author, Department of Philosophy, University of California, One Shields Avenue, Davis, CA 95616-8673.

$\ddagger$ This work germinated during fellowships at the Wissenschaftskolleg zu Berlin (199293) and Collegium Budapest (1994-95). I thank the Rektors and Fellows and the respective Biology Group Conveners, Peter Hammerstein, and Eörs Szathmáry. This work would not have been done without the interest and support of Leo Buss, Eva Jablonka, Evelyn Fox Keller, Ross Kiester, and Eörs Szathmáry. I thank Peter Godfrey-Smith for organizing the symposium and audiences in Berlin, Chicago, Duke, Jerusalem, Northwestern, and San Diego. I thank especially my former colleague Michael Dietrich for many helpful discussions and Connie, Ellen, and Kate for their support. Financial support of USDA Cooperative Agreement PNW 95-0768 and UC Davis Faculty Research Grants is gratefully acknowledged.

Philosophy of Science, 67 (Proceedings) pp. S348-S368. 0031-8248/2000/67supp-0028 $\$ 0.00$ Copyright 2000 by the Philosophy of Science Association. All rights reserved. 
our scientific interests in them are heterogeneous, and the number of possible ways of representing them in models is large. Our representations no more sort into simple compositional levels of organization than do the phenomena themselves (Wimsatt 1974). We need the discipline of perspectives to coordinate our efforts to represent. In the most interesting cases, a variety of perspectives as well as models will be required for adequate theorizing.

Images express theoretical perspectives in that they specify preferred lines of abstraction from phenomena of interest and also prioritize principles in terms of which models may be constructed to represent phenomena (Fig. 1). Images give concrete expression to a perspective, showing or saying what matters most about phenomena in relation to our interests in representing and intervening into phenomena. Genetic determinism is a prime example of a perspective and Weismannism is one of its important images.

The developmental systems perspective (DSP) formulated by Oyama, Gray, Griffiths and others seeks to replace the perspectives of genetic de-

\section{EXTENDED GIERE MODEL OF SCIENTIFIC REASONING}

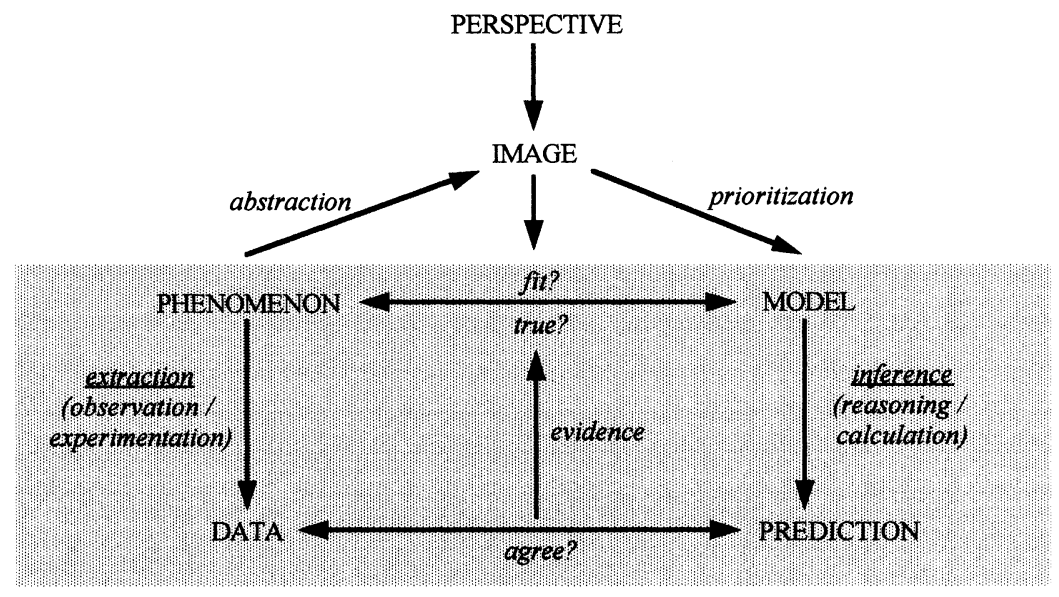

Figure 1. Extended Giere Model of Scientific Reasoning. Perspectives and Images are added to Giere's model of scientific reasoning. Shaded portion redrawn after Giere 1997, Fig. 2.9. Images, the concrete expressions of theoretical perspectives, coordinate phenomena and models by specifying relevant respects and degrees of fit. Coordination is important in both representation of phenomena by models and in planned interventions into nature to produce experimental and observational data and predictions. Images abstract from phenomena and also prioritize principles that go into explanatory and phenomenological components of models. 
terminism and gene selectionism (Oyama 1985, Gray 1992, Moss 1992, Lewontin 1993, Griffiths and Gray 1994, Neumann-Held 1998). DSP replaces the image of genes as privileged molecules that control development as well as their own evolutionary fate through active germ-line replication. DSP rejects:

1. the dichotomy of genes vs. other developmental resources in favor of a causal democracy of many kinds of resources equally necessary to produce developmental outcomes;

2. the privileging of genes over other developmental resources in causal explanations of development and evolution through identification of genes as the sole coded information-bearers that "program" phenotypes, in favor of a symmetry in which it makes no more sense "to say that the other resources 'read off' what is 'written' in the genes than that the genes read off what is written in the other resources" (Griffiths and Gray 1994, 284); and

3 . the deflationary argument that genes rather than higher level entities such as organisms or whole developmental systems are the primary units of replication because extended phenotypes can always be analyzed in terms of marginal causal contributions of privileged developmental system components (Griffiths and Gray 1994, 289, contra Sterelny and Kitcher 1988; cf. Wimsatt 1980 on "bookkeeping arguments").

Theories, in contrast to perspectives, are collections of models and their robust consequences (Levins 1968). Developmental systems theory (DST) offers descriptive models to represent and interpret phenomena that are also represented by genetic models from the perspective of genetic determinism and selectionism. For example, Griffiths and Gray $(1994,278)$ suggest ways to delimit and individuate developmental systems. One such model concerns developmental resources: those resources are parts of a developmental system "whose presence in each generation is responsible for the characteristics that are stably replicated in that lineage" (1994, 286). Another concerns ultimate rather than proximate causes in nature: the interactions "that produce [developmental] outcomes with evolutionary explanations are part of the developmental system" $(1994,286)$.

These models can be used to interpret many phenomena of developmental and behavioral evolution provided replication can be properly interpreted within the developmental systems perspective. Griffiths and Gray claim that "evolution is best construed as differential replication of total developmental processes or life cycles" $(1994,278)$. In expressing a model of the unit of replication, Griffiths and Gray formulate a developmental systems theory.

A central goal of DST is to explain the transgenerational stability of 
form, while not attributing this to the transmission of a genetic blueprint or program (Griffiths and Gray 1994, 286), so a premium is placed on finding an alternative to the familiar idea that transmission is genetic, as Oyama (1985) emphasized.

My concern in this paper is with DST's shift of units of replication from genes to developmental systems, its model of replication, and implications for interpreting cultural in relation to biological evolution. Critics of DST, such as Sterelny, Smith, and Dickison (1996), want to get off the DST "inference bus" at an intermediate stop where their less radical perspective of extended replicators (ERP) is located (Fig. 2). Griffiths and Gray's (1997) reply that the intermediate stop on the DSP line is no less radical an end point than DST supports my view of these matters. The results of this paper imply that Sterelny et al. are on the wrong line, so getting off at an intermediate stop fails to improve things. That line, common to ER and DST, subsumes replication under the developmental systems perspective. Whether one gets off at an intermediate stop or the end of the line is beside the point because the subsumption happens at the first stop. I suggest instead that DSP, ERP, and my own view are species of process perspectives on reproduction, not only on development. Thus, I am in sympathy with Sterelny, Smith and Dickison's suspicion that something is wrong with DST but skeptical of their extension of replicators. Genes may not be privileged as master controllers of development and heredity, but there is still something more to the distinction of genes from other kinds of developmental resources. I will argue that this distinction is best reached on the reproducer line after transferring off the Gene's Eye/ Extended Replicator line.

I will sketch a process perspective for interpreting replication that is friendly to DSP's emphasis on developmental process and variety of resources, but I reject Griffiths and Gray's conclusion that "the developmental systems view makes it impossible to maintain the distinction between biological and cultural evolution" (Griffiths and Gray 1994, 278 279). I aim to improve on DST's model of replication in support of DSP's theoretical and empirical goals, though I will not be offering empirical applications here.

2. Deprivileging Genes, Privileging Replication. DSP's deprivileging of genes, along with DST's model of units of replication, led Griffiths and Gray (1994) to claim in their introduction that there is no basis left for any distinction between cultural and biological evolution. A more modest claim appears toward the end of their paper. They write, "The developmental process view changes the relationship between biological and cultural evolution. This distinction rests on a distinction between genetically 
Stops on the DST Inference Bus Line

Stop 1. On each developmental cycle in an organism lineage, many important elements of the previous cycle are reliably rebuilt/repeated. These constancies permit selection to be cumulative.

Stop 2. The developmental process is complex, with effect of each element depending on the effects of many others. If genes controlled, directed or were the organising centre of development, they would still have a privileged role and could be considered the replicators.

Stop 3. The notion of genetic information cannot be made good in a way that singles out genes as having particular significance; genes predict phenotypic traits only in the same sense that environmental factors predict them.

Stop 4. No causal selection scheme picks out genes, either in the development of a single phenotype in the lineage, nor in its recreation in the next link in the lineage.

Last Stop - DST. Nothing singles out genes as special, hence genes are not the replicators; whole developmental systems are.

Figure 2. Stops on the DST Inference Bus Line. Sterelny, Smith and Dickison (1996) map the bus line they attribute to DST. They want to get off at stop 3 rather than ride to the end of the line. In distinguishing DSP from DST, I have corrected the characterization of the end of the line as stopping at DST rather than at DSP.

transmitted and environmentally acquired traits" (Griffiths and Gray 1994, 301).

Genetic/environmental, innate/acquired, transmitted/persistent are dichotomies that Oyama (1985) sought to undermine in her formulation of 
DSP. While sharing this goal, Griffiths and Gray's paper reflects their theoretical additions to DSP. Deprivileging genetic resources in developmental and evolutionary explanation entails a lack of theoretical distinction between biological and cultural evolution, only insofar as the model of replication assumed by the theory distinguishes between traits genetically transmitted and environmentally acquired. DST rejects that distinction, but its model of replication is too vague to draw any strong conclusions about the relation of biological and cultural evolution. We must be able to distinguish material from dynamical conditions in evolutionary processes in order to sustain the distinction. With a different model of replication, backed by the reproduction process perspective developed in Section 4, an interesting distinction between biological and cultural evolution can be sustained. This perspective helps to characterize the difference between DSP and extended replicator perspectives (ERP). DSP and ERP have differing explanatory priorities. DSP focuses attention on developmental processes rather than on structures of developmental systems.

The distinction between genetics and learning, like the image of Weismannism generally (Fig. 3; see Griesemer and Wimsatt 1989), both distinguishes and privileges the role of genes. Process perspectives may avoid causal privileging, as DSP requires, while maintaining distinction between biological and cultural evolution. This is possible by recognizing different kinds of cultural evolution in terms of both material conditions for cultural reproduction and dynamics.

Support for DST's argument that whole developmental systems or processes (life cycles) are the units of replication requires an articulate model of replication. Although Dawkins (1982) says replicators are merely things of which copies are made, his notion of active, germ-line replication is more precise than DST's notion of re-occurrence of developmental resources in life cycles. Dawkins's explicit adoption of Weismannism as the guiding image for causal structure in processes of heredity and development $(1982,164)$ grants causal specificity as well as privilege: we know how as well as that gene privilege is supposed to work. DST does distinguish among modes of repetition of kinds of developmental resources in life cycles in which relationships created by interactions among resources are replicated. However, until these distinctions are incorporated into specific ecological models of developmental resource interaction, replication of developmental systems remains vague.

In DST, replication appears to be any recurrence, repetition, reconstruction, persistence, or combination of these across generations of life cycles of relationships created by developmental interactions. Sterelny, Smith, and Dickison $(1996,389)$ rightly worry that DST must surely go wrong if it treats all reappearances of developmental resources (or even relationships) as replications. These critics argue that only those resources 


\section{WEISMANN AND THE CENTRAL DOGMA}
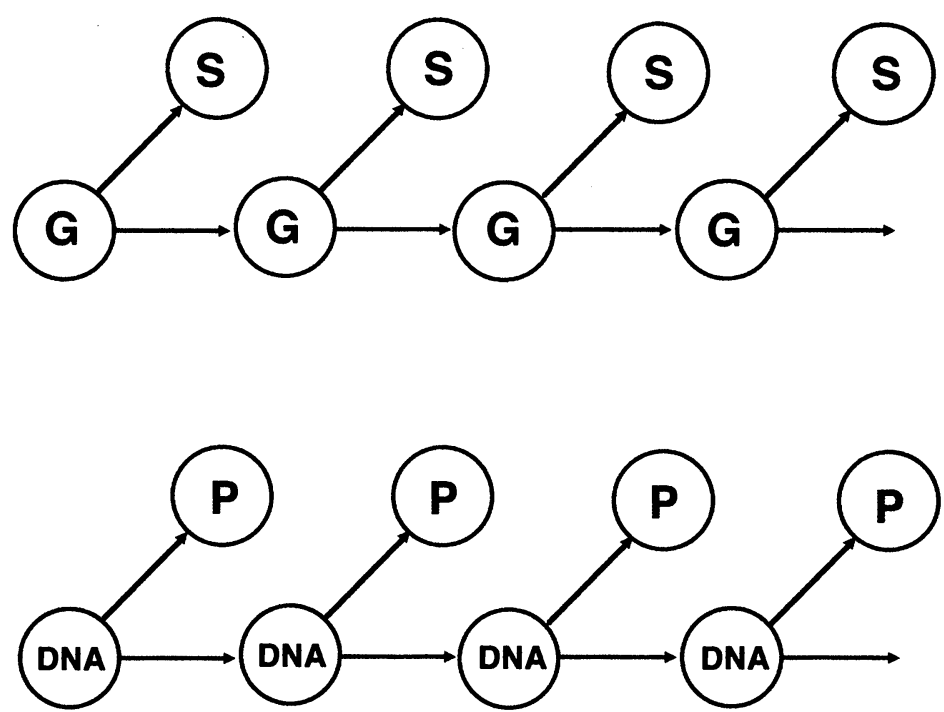

Figure 3. Image of Weismannism (redrawn after Maynard Smith 1975). Weismannism expresses the causal logic of germ and soma, gene and protein. Germ/DNA exhibit genetic continuity across generations and also are the causes in development of soma/protein. Genes are therefore the primary causal explainers of development, heredity and evolution.

with developmental biofunctions, i.e., adaptations for development, with the function of ensuring cycle to cycle similarity, are replicators. There is something right in this criticism. Pressure to clarify the nature of replication as a process in relation to development must be taken seriously. Whether the biofunctional approach is the right one to take is another question.

Griffiths and Gray sometimes talk about particular resources being replicated, at other times about whole systems of developmental resources being replicated, sometimes about the expansion of replicator status to include resources of many kinds, sometimes to the replacement of genes by whole developmental systems as the sole units of replication. At least it is clear in Dawkins's model that organisms are not replicators. At issue in DST is whether anything or everything is a replicator, not only the development of individuation criteria that admit whole developmental systems or processes among the replicators.

Sometimes Griffiths and Gray seem to adopt Dawkins's meaning in 
order to extend it, at other times they appear to reject it outright as antidevelopmental. They are not the only theoreticians with a problematic relationship to Dawkins's work. Sterelny, Smith, and Dickison criticize Dawkins's account of replicators, but then help themselves to his examples to support their extended replicator view as sharing heuristic advantages with Dawkins's gene's eye view. These troubles are symptoms of vagueness in the analysis of replication, which must be clarified in order to make progress toward empirically useful theories within DSP or from a process perspective more generally.

3. The Unit(s) of Replication. I take it that this vagueness is a vestige of Dawkins's replicator concept being based on properties and behavior of a particular kind of structural unit-the molecular gene-for which he gave an evolutionary-functional definition. Extended replicators might have served as a basis for developmental systems theory, but not for developmental processes theory. I have argued elsewhere that DNA "replication" is not a paradigm copying process, so if copying is the essence of replication in Dawkins's definition, DNA is not a good basis for extending the replicator (Griesemer in press). DST must include a processual model of replication. Worries about the units of replication are subsidiary empirical problems.

At the same time, Griffiths and Gray are very careful to distinguish among developmental resources, systems, and processes and among the modes of reappearance of developmental resources in subsequent life cycle "generations." They distinguish among persistent, individual actively replicated, and collectively replicated developmental resources. All three modes of reappearance are included in the replication of total developmental systems or processes. Moreover, developmental systems can embed so that small, replicating systems can be parts of larger systems in which they are involved (Griffiths and Gray 1994, 294-295). Developmental systems of comparable scale can even embed one another: each member of a mutualism plays interactor to the other's replicator (Griffiths and Gray 1997). They argue that whole developmental systems or processes are the unit of replication because genes cannot be privileged in developmental or evolutionary explanation and that the resources required to explain in either domain extend beyond the parental resources that cycle in synchrony with genes (Griffiths and Gray 1994, 292). Persistent resources, insofar as they play a role in interactions, must also be included as parts of developmental systems. The fact that their mode of stable repetition, generation after generation, is persistence rather than active replication is irrelevant to the repeated reassembly of offspring organisms and developmental outcomes. Even if persistent resources are not themselves rep- 
licators, the relationships among developmental interactants, including persistent resources, are (Griffiths and Gray 1997).

In order to head off the kind of privileging made by Dawkins's gene's eye view of evolution, DS theorists have argued that deprivileging leaves only the whole DS, not genes, as the units of replication. The effects of gene activation in development reappear in subsequent generations only in virtue of systematic dependency on the relevant environmental and nongenetic conditions in which gene activation takes place. But what is it for a whole developmental system to replicate? If it means nothing more than that the properties of the system reappear in offspring systems, then we have learned nothing more than that there is a non-zero parent-offspring correlation in those properties. Surely replication means more than just correlation, even if genetic information can be reduced to transgenerational correlation or systematic dependency within developmental systems. Is replication now so privileged that we must see developmental systems doing it even after the causal privilege and specificity of gene replicators has been rejected? Why do we need the concept of replication at all?

4. The Reproductive Process Perspective. I turn now to some distinctions that will help understand the nature and role of replication in a process perspective. Oyama (this symposium) writes:

In DSP heredity includes all developmental interactants or resources, which become available to [the] next cycle in a variety of ways. Phenotypic traits are developed, not inherited ... Resources are "transmitted"- -become available; organisms are constructed in systemic interactions. (italics added)

I distinguish between heredity and inheritance in a particular way in order to keep certain relations, capacities, and processes distinct. I reserve the word 'heredity' to refer to parent-offspring relations. The degree of a heredity relation is measured by parent-offspring correlations. By 'heritability' I mean the capacity of a trait to cause a relation of heredity in a particular degree. 'Inheritance' refers to a kind of process in which heritabilities are realized and thus heredity relations instantiated. 'Inheritance' names a particular kind of reproduction process and 'replication' names a particular kind of inheritance process. These views lead me to a conclusion contrary to Oyama's statement quoted above. Development is not an alternative to inheritance in the explanation of phenotypic traits.

4.1. Heredity of Developmental Resources. The full range of developmental resources may exhibit relations of heredity on lineages of life cycles. These relations are of several different kinds: persistence, recurrence, de- 
velopment, contruction, and returns. In other words, the modes of production of re-occurrences or repetitions of developmental resources are types of causes of heredity relations (Fig. 4). These modes are caused by various capacities distributed in the world among various kinds of actants

\section{MODES OF PRODUCTION THAT CAUSE HEREDITY OF DEVELOPMENTAL RESOURCES}

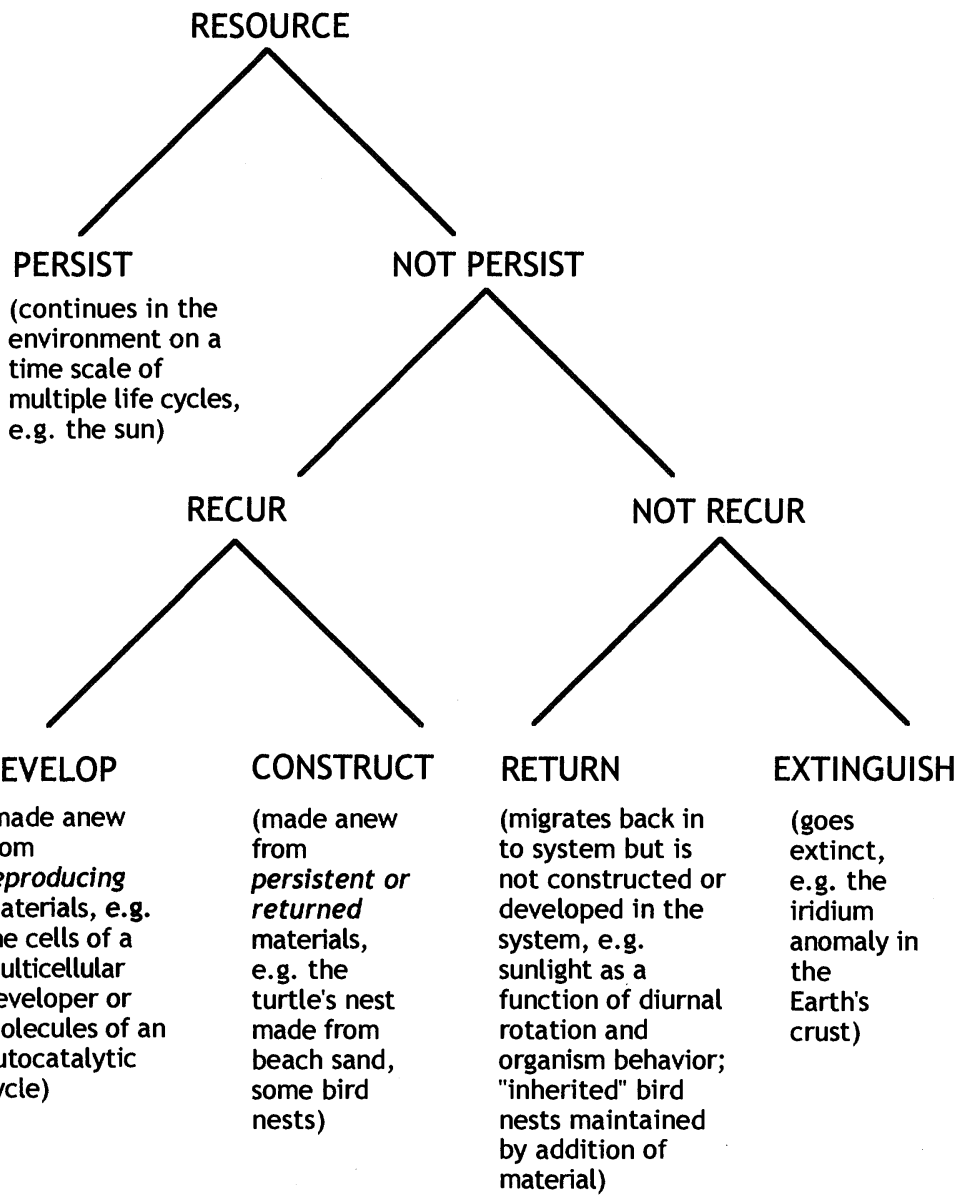

Figure 4. Modes of Production That Cause Heredity of Developmental Resources. The various types of recurrence sought in the developmental systems perspective are classified. See text for discussion. 
and agents. Note that replication is not among these modes because replication is a process, not a capacity or a relation.

The words 'reoccurrence' and 'repetition' are misleading. They suggest heredity relations in perfect degree, which need not be the case. Talk of "species typicality" in the DSP literature is talk about relations of similarity in perfect degree that may stem from this misleading way of interpreting developmental outcomes. It should be no part of a theory of the heredity relation, heritability capacity, or process of replication that any particular degree of the heredity relation must be realized. It is, of course, of special interest to developmental evolutionists to explain the stability of reliably repeated transgenerational form, but this is only one class of evolutionary developmental outcomes. Although rotting may be the species-typical outcome of acorn development, whether rot or oak results is not germane to the theory, only to the empirical evaluation of outcomes. It is just as risky for DST to embed a notion of species-typicality in its theory as for Dawkins to build his replicator concept around copy-fidelity. Genealogy, not similarity, is the fundamental basis for evolutionary theories with maximum explanatory power.

For this and other reasons, I want to interpret the stakes in a theory of development more narrowly than DSP does. I seek a minimum conception of development with which to bound theories of evolution. What does evolutionary theory minimally require of a theory of development? I take species-typicality to be an evolutionary maximum concept. I seek the weakest and strongest concepts of "re-occurrence" or "repetition" required by a general theory of the evolutionary process. This approach is in line with Griffiths and Gray's observation that such a model of development will not answer all developmental questions (1994). But it will answer some very important ones (see also Griesemer 2000).

Instead of subsuming all resources under the process of development, in my process perspective all resources are subsumed under the process of reproduction, only some of which will count as developmental resources. In my taxonomy, resources are classified according to modes of production in processes of different kinds rather than in terms of outcomes in the process of development. My goal is to interpret the relationship between processes of development and reproduction.

A rough taxonomy of the types of resources mentioned by Griffiths and Gray shows that development is one mode of the heredity of resources (see Fig. 4). Development is a process that involves reproduction. I argue that reproduction is a process that involves development. The relation of reproduction and development is not circular, but recursive. This recursive property shows us where to look for the structures we call levels of organization. These levels are ontological insofar as they are themselves products of evolutionary transition (Maynard Smith and Szathmáry 1995) 
rather than epistemological constructs based on models of anatomical (compositional) structure or evolutionary function.

4.2. Reproduction Processes. All biological reproduction processes have two fundamental aspects that can be expressed in terms of the realization of intertwined capacities: a specialized form of multiplication that I call "progeneration" and development (Griesemer 2000). 'Progeneration' is a neologism I use to distinguish multiplication from transmission, which has quite different and historically misleading connotations.

Multiplication leads to a numerical increase of individuals. Progeneration, in general, leads to an increase of individuals "of the same relevant kind." Development is the process by which sameness of kind is realized, often despite substantial variation-producing forces. In the restricted domain of evolutionary processes, what counts as the same (relevant) kind?

It is not necessary for present purposes to make a firm choice, but only to examine the bounds and to use them to express the role of development in relation to heredity in evolution. Here I want to formulate a view of the lower bound, of the evolutionary minimum concept of development. Relationships among the concepts described are shown in Figure 5.

One clue to a concept of evolutionary minimum relevant sameness is that increase in numbers due to multiplication is always multiplication with "material overlap." This is progeneration in a general sense: the kinds of materials specify relevant sameness. Material overlap means that some of the parts of the offspring were once parts of the parents. Material overlap is the relation that results from the flow of matter which creates genealogy. In politics you follow the money, in biology you follow the stuff. If you cut a loaf of bread in half, you make two new things out of one old one. In this case, all the parts of the new half-loaves were formerly parts of the old loaf (except for the crumbs on the cutting board). Segregation of parts does not imply that the new things are loaves. If a cell reproduces by binary fission, it divides into two new cells, all of whose initial parts had once been parts of the parent. If two sexual parents mate, the offspring results from a material merger of parental gametes.

In biological reproduction there is always a genealogy-creating flow of matter. This involves the transfer, not of unorganized "modeling clay" for the creation of offspring statuary; instead, organized physical parts of parents at one time become organized physical parts of offspring at other times. No mere transfer of pattern or structure, as in crystal growth, without material transfer is sufficient for reproduction. In addition to general progeneration there is a special, developmental form of progeneration: multiplication with material overlap of certain kinds of organized, physical parts which we can call "pieces" or mechanisms of development (Wal- 


\section{MODES OF MULTIPLICATION}

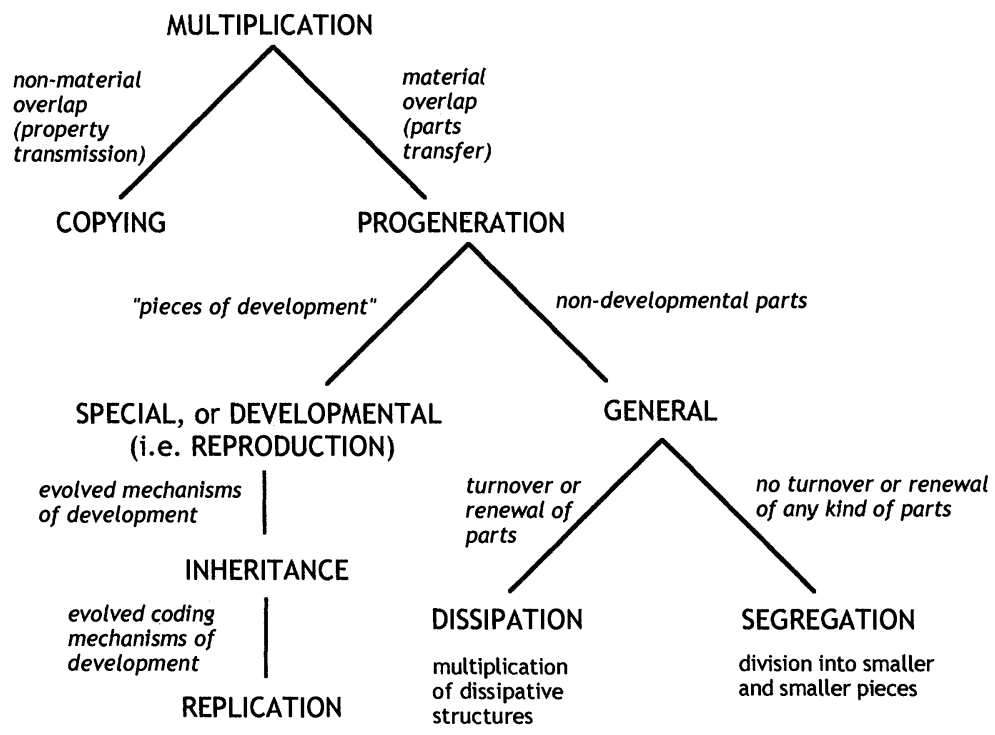

Figure 5. Modes of Multiplication. Processes of replication, inheritance, and reproduction-species of special or developmental progeneration-are shown in relationship to processes of copying, dissipation, and segregation. All are modes of multiplication, the numerical increase of individuals.

ter Fontana's phrase). Developmental progeneration is another name for biological reproduction.

- Material overlap distinguishes reproduction from "copying." In copying, structure is transmitted from an original to a copy. Copies and originals do not necessarily have a genealogical relationship caused by material overlap. Compare a photocopy of a painting (copying) with half of the torn canvas of the original (progeneration) with each other and with the original. It is easy to see that while both processes create similarity, the respects and degrees of resemblance are in general quite different.

4.3. Evolutionary Minimum Concept of Development. The evolutionary minimum concept of development is the acquisition of the capacity to reproduce. Being of the same relevant kind means being of the reproducing kind, i.e., having the capacity to reproduce. No particular degree of resemblance in any particular trait is required in general for reproduction to operate. Of course, realization in offspring of the capacity to reproduce will undoubtedly entail many particular trait resemblances. Moreover, 
particular trait heritabilities and variations must be present in a population for evolution to work. But only a general theory of development could identify universal or common resemblances beyond the bare capacity to reproduce, let alone species-typical traits.

Offspring typically are not born with the capacity to reproduce, but must acquire this capacity. If development is the acquisition of the capacity to reproduce, then offspring may be born with the capacity to develop. To be a "reproducer" like its parents rather than a mere bodily byproduct, the pieces of development that are passed on in progeneration must confer the capacity to develop on the offspring. When progeneration transfers "pieces of development," parents generate offspring reproducers.

Material propagules are a good way to transfer capacities, which generally require the exercise of mechanisms - organized collections of material parts that cause behavior (Glennan 1996). Passing "blueprints" or representations of development instead relies much more heavily on the conditions at the receiver for reliable transmission to occur, since the receiver must already have the capacity to act on receipt of the blueprint. Thus relevant sameness is further specified: material overlapping parts conferring the capacity to develop.

These ideas about progeneration, development, and reproduction can be summarized as follows. Special or developmental progeneration is multiplication with material overlap of mechanisms conferring the capacity to develop. Development is acquisition of the capacity to reproduce. Reproduction, therefore, is progeneration of entities that develop.

Since development is analyzed in terms of the capacity to reproduce and progeneration transfers the capacity to develop, reproduction can be understood as the recursive realization of the capacity to reproduce. The capacity to reproduce is the capacity to progenerate entities with the capacity to acquire the capacity to reproduce. Reproduction requires both progeneration and development. The recursion is complex because of the way these capacities intertwine (see Table 1).

The reproduction of a multicellular organism involves the organism's ontogeny from an embryo or zygote. This development typically involves growth and cell differentiation, which usually involves cell reproduction. Cell reproduction involves the development of a cell from its initial fission state to a state in which it is capable of dividing. This reproductively capable cell state will involve the growth of membrane, increase of cytoplasm, reproduction of organelles and chromosomes, and so forth. But what, exactly, is at the bottom of the recursion, where something must be progenerated that does not need to acquire the capacity to reproduce by development, but which has it automatically, in virtue of having been born?

The recursion "bottoms out" at a level of reproduction where the 
TABLE 1. Reproduction

\begin{tabular}{|c|c|c|}
\hline & Process & Capacity \\
\hline Progeneration & $\begin{array}{l}\text { multiplication with material } \\
\text { overlap of mechanisms } \\
\text { conferring the capacity to } \\
\text { develop }\end{array}$ & $\begin{array}{l}\text { the capacity to progenerate entities } \\
\text { with the capacity to develop }\end{array}$ \\
\hline Development & $\begin{array}{l}\text { acquisition of the capacity to } \\
\text { reproduce }\end{array}$ & $\begin{array}{l}\text { the capacity to acquire the } \\
\text { capacity to reproduce }\end{array}$ \\
\hline Reproduction & $\begin{array}{l}\text { progeneration of/by entities that } \\
\text { develop }\end{array}$ & $\begin{array}{l}\text { the capacity to progenerate entities } \\
\text { with the capacity to acquire the } \\
\text { capacity to reproduce }\end{array}$ \\
\hline Inheritance & $\begin{array}{l}\text { reproduction with material overlap } \\
\text { of evolved mechanisms of } \\
\text { development }\end{array}$ & \\
\hline Replication & $\begin{array}{l}\text { inheritance with material overlap } \\
\text { of evolved, coding mechanisms } \\
\text { of development }\end{array}$ & \\
\hline
\end{tabular}

"pieces of development" transferred by progeneration are all in place, operating and ready to go all the time; no further acquisitions via nutrition, metabolism, growth, differentiation, conditioning, or situating are required. This condition may be called "null development." In fact, Weismannism, upon which the Received and Gene's Eye Views are based, treats germ cells as null developers: the soma may be necessary for replication to be differential but replication per se looks like it could happily go on without separate vehicles at all (see Fig. 3).

A good candidate for null development is chemical autocatalysis, in which any cycle element can regenerate the cycle without requiring any kind of chemical modification of its own structure. How wide the inevitable ceteris paribus clause must be to make sense of null development is an important empirical question. It is significant that there are models of proto-organisms which are decomposable into stoichiometrically interdependent autocatalytic systems (Morowitz, Heinz, and Deamer 1988; Maynard Smith and Szathmáry 1995; Gánti 1997).

The recursive nature of the definition of the capacity to reproduce shows how the process of reproduction can be the basis for hierarchical structure: each level of the recursion is a level of reproduction and the realization of the process at a level requires its realization at every lower level until null development is reached. Below the level of null development are levels of process that may contribute to reproduction, but which need not be reproduction processes themselves.

4.4. Inheritance Processes. Offspring need not resemble their parents in any particular traits in order for parents to have successfully conferred the capacity to reproduce. Parents can be non-winged while offspring are 
winged. Parents can be asexual while offspring are sexual. And so on. The claim is not that there are no particular respects in which offspring reproducers resemble parent reproducers beyond the bare capacity to reproduce, but only that the evolutionary minimum specification of development bounds what we currently know of development on the ignorance end of the spectrum - we know that development must at least be the acquisition of the capacity to reproduce. A general theory might bound what we currently know of development on the other end with some concept of species-typicality.

These remarks about heritability can hardly be understood if one's conception of hereditary transmission is based only on the highly regulated, highly evolved, modern nucleic acid "replication" system. We take for granted that transmission fidelity must be high for a mechanism/system to count as genetic, but that is only because the modern DNA system is high-fidelity and nearly universal in the contemporary world. If hereditary transmission is necessarily high-fidelity, then it could not have evolved; the Eigen error catastrophe could not have been overcome (see Maynard Smith 1986).

So long as the components of development by which the capacity to reproduce is acquired result in component transmission fidelities greater than zero there is scope for evolution to operate among them. Populations of reproducers have the capacity to evolve, insofar as the pieces of development that realize their reproductive capacities themselves have heritable properties that vary. For reproducers at a given level to be units of evolution, their developmental component parts must also be reproducers.

Let us describe this situation in terms of a special kind of reproduction process: an inheritance process. Inheritance is reproduction with material overlap of evolved component mechanisms of development (see Table 1). (In what follows I assume the evolution is adaptive.)

Understanding the relation of inheritance and reproduction processes is facilitated in the context of the theory of evolutionary transitions (Maynard Smith and Szathmáry 1995). Evolutionary transition creates new levels of reproduction - emergent reproducers (Szathmáry and Maynard Smith 1997). Once a new level originates, evolution by natural selection can operate, at first inefficiently due to low fidelity, on the reproducers at that level. If it does so, the consequence will be the evolution of mechanisms for development, i.e., for efficient, adaptive acquisition of the capacity to reproduce, at that level. Thus, component mechanisms of development will be adaptations for development of the reproducers at that level. Reproducers at an emergent level may evolve into units of inheritance at that level.

Because the mechanisms of development in inheritance processes are adapted-refined to serve component functions in development better- 
fidelity of transmission (heritability) of component traits of the phenotype can increase. This increase may be necessary to produce the kinds of highly articulated developmental components we see in advanced organisms such as eukaryotes that coordinate the developmental and reproductive behavior of a community of symbionts, multicellulars that coordinate behavior in communities of communities of symbionts, and perhaps on up to still higher levels of reproductive organization (see Wade and Griesemer 1998).

4.5. Replication Processes. The familiar replication processes of modern organisms depend on the highly evolved system of linear coding in the nucleic acid mechanisms for development. Although coding and the cybernetic language of information have played an ambiguous and poorly understood role in the interpretation of genetic processes (Keller 1995, Sarkar 1996, Kay 1998), I believe this largely has to do with the fact that coding tends to be interpreted in terms of code structure rather than in terms of coding process.

I cannot enter here into a discussion of the nature of coding or try to rescue it from the bad old rhetoric on genetic information, but I will use it anyway to define a replication process. A replication process is an inheritance process with material overlap of evolved, coding mechanisms of development (see Table 1). Genes alone do not suffice for a replication process. They do not constitute mechanisms of development that confer the capacity to develop. Genes are, instead, pieces of such mechanisms. As pieces of mechanisms, they cannot have the privileged status accorded them by genetic determinists. Similarly, coding is not a property of genes, but of the mechanisms of development in which genes play a role.

One reason to subsume replication processes under inheritance processes (Fig. 5, Table 1) in terms of coding is that coding connotes a precise kind of mechanism of development, one that is likely to play some role in high-fidelity, high-reliability transgeneration heredity relations.

5. Biological and Cultural Evolution. A key difference between Dawkinsreplicators and reproducers is that the former are grounded in similarity, the latter in genealogies of material overlap.

Material overlap is one way of making reliable the transmission of the capacity to develop. Packing structure into a material propagule stabilizes the transmission process to a range of conditions rather than making transmission depend on stability of the channel conditions to insure reliable outcomes. Propagules such as DNA molecules, chromosomes, cells, even whole organisms migrating from one population to another, are all complexes of material organized in precise ways. If progenerative structure is to be repeated in the next generation's life cycles, it must get into them 
somehow. Packing more resources into the propagule renders transmission reliability less dependent on the rest of the system. Provisioning an egg is a way of avoiding dependence on the persistence, recurrence, or return of food sources for a time. We can expect dynamic trade-offs among the various possible places in a developmental system as understood by DSP to stash resources and these will be reflected in the diversity of the evolved biota. More yolk in the egg may mean slower cell division.

In a photocopying machine, the structure of the environment of the photocopyable material is very complex. Compare the complexity of the paper input to that of the copy machine itself. The paper original that goes in and the one that comes out are relatively simple. More importantly, because there is no material overlap of original and copy, the entire structure of the original must be carried by the paper's "environment" during transmission in order to transfer it to a copy. Such components are necessarily more complex than the patterns they carry because the patterns become parts of the environmental structure for a time. The copy machine must stably and reliably hold the structure of the original (electrostatically on the copier's drum) and then construct it on the output paper. Paper copies could not be made but for the complexity of their "environments." If one is tempted to think that copy machines are not more complex than paper encoded "memes" because the latter have cultural encoding systems such as language, just consider that the machine is not the only system component relevant for measuring complexity: others include maintenance and repair personnel to tend the box and keep it running, parts and supplies networks and, in short, the full range of returning, recurring, and persisting resources.

Electronic communication, e.g., via telephone wires, trades off the simplicity of message syntax (encoded in temporal patterns of electrons) against the semantic and pragmatic complexity of source, receiver, and channel conditions needed to make the temporal pattern reliably receivable. Dawkins is right to point to the differences between digital and analog coding devices when he extols the virtues of nucleic acid replication and digital computers, but he underestimates the significance of the difference between them: material overlap in nucleic acid systems of replication means that the channel conditions can be very much simplified and still get relatively reliable transfer. That simplicity is misleading, however, if the packaging of the copying machine itself into a propagule- the germ cell or embryological "bootstrap" (Dawkins 1995) - passes unnoted.

Finally, I have reached the target of this paper: the claimed lack of distinction between biological and cultural evolution by proponents of DST. The steps in the argument for this claim are straightforward. (1) DST has deprivileged the gene as replicator and therefore whole developmental systems (processes, life cycles) are the units of replication. 
(2) If there is no principled distinction among kinds of resources that serve as the replicators, then there can be no principled distinction between replicators and interactors. (3) Insofar as cultural evolution is either evolution of interactors that is autonomous from evolution of biological replicators, or is evolution among replicators distinct from genes, cultural evolution does not exist as a distinct category from biological evolution.

In light of the account of reproduction in Section 4, we understand replication differently. Replication is inheritance with coding mechanisms of development. Inheritance is reproduction with evolved mechanisms of development. Since replication processes are reproduction processes, they must also satisfy the material overlap requirement for reproduction.

Material overlap gives us a way to distinguish biological from cultural evolution. More precisely, it gives us a way to distinguish different forms of what is called cultural evolution, for this is a heterogeneous class. Griffiths and Gray are right to claim that the relation between cultural and biological evolution is changed in DSP. From the reproductive process point of view, systems that satisfy the requirements of units of evolution and are reproducers will be subject to biological evolution. Evolutionary patterns and processes that do not have reproducers as units are nonbiological. Material overlap gives meaning to "biological."

Many cases interpreted by DSP and ERP proponents, e.g., nest and burrow evolution, are biological because they meet the material overlap and other conditions of the reproducer analysis. But other cases may not. They may not involve the material overlap of mechanism-carrying propagules that confer developmental capacity on offspring life cycles. There may be energy transfers rather than material overlaps which imply that a whole "cultural system" including the complex of resources external to a set of memes counts as a developmental system. These may be cases of non-biological cultural evolution under the right conditions of variation and fitness differences.

One place where DST, as developed by Griffiths and Gray, is quite helpful, is in drawing attention to problems of individuation of developmental systems and processes. Determining whether an evolutionary process involves material overlap of propagules requires principles of individuation.

Thus, some cases of evolutionary change that have been interpreted as cases of cultural evolution may exhibit heritability of developmental outcomes caused by reproduction and others not. But what difference does this distinction make? First of all, we can expect reproducers to have significantly different evolutionary dynamics than do nonreproductive copying systems due to differing constraints on transfers of matter vs. energy at macroscopic scales. The stabilities and periodicities of matter transfer are likely to differ from those of energy transmission. Electronic com- 
munication over the Internet has quite different dynamics, for example, than electronic communication by snail-mailing floppy disks.

Second, reproducers can behave as very different kinds of developmental resources than non-reproducers, relative to other parts of a developmental system, because reproducers may interact with other reproducer parts quite differently than persistent or recurrent resources may. Reproducers may reproduce with other reproducers to generate new parts of a developmental system. This difference between reproducer and nonreproducer parts of a developmental system should allow us to distinguish among types of cultural evolution even if the dynamics at a given level of reproduction or copying of component parts of a developmental system are fairly similar. Plants relying on the sun as a persistent resource may have similar contemporary ecological dynamics to birds relying on abundant insect prey, but it is likely that long-term evolutionary dynamics of plant-sun and bird-insect systems are different. If developmental interactions, the heart of the process view of DSP, can be distinguished into reproductive and non-reproductive dynamics, then a distinction between biological and cultural evolution is justified.

\section{REFERENCES}

Dawkins, Richard (1982), The Extended Phenotype. New York: Oxford University Press. (1995), River Out of Eden, New York: BasicBooks.

Gánti, Tibor (1997), "Biogenesis Itself", Journal of Theoretical Biology 187: 583-593.

Giere, Ronald (1997), Understanding Scientific Reasoning, 4th ed. Fort Worth, TX: Harcourt Brace College Publishers.

Glennan, Stuart (1996), "Mechanisms and the Nature of Causation", Erkenntnis 44: 49-71.

Gray, Russell (1992), "Death of The Gene: Developmental Systems Strike Back", in Paul Griffiths (ed.), Trees of Life. Dordrecht: Kluwer Academic Publishers, 165-209.

Griesemer, James R. (in press), "The Informational Gene and the Substantial Body: On the Generalization of Evolutionary Theory by Abstraction", in Nancy Cartwright and Martin Jones (eds.), Varieties of Idealization. Poznan Studies (Leszek Nowak, series ed.). Amsterdam: Rodopi Publishers.

. (2000), "Reproduction and the Reduction of Genetics", in Peter Beurton, Raphael Falk, and Hans-Jörg Rheinberger (eds.), The Concept of the Gene in Development and Evolution, Cambridge: Cambridge University Press, 240-285.

Griesemer, James and William Wimsatt (1989), "Picturing Weismannism: A Case Study of Conceptual Evolution", in M. Ruse (ed.), What the Philosophy of Biology Is, Essays for David Hull, Dordrecht: Kluwer Academic Publishers, 75-137.

Griffiths, Paul and Russell Gray (1994), "Developmental Systems and Evolutionary Explanation", Journal of Philosophy 91: 277-304.

- (1997), "Replicator II-Judgement Day", Biology and Philosophy 12: 471-492.

Kay, Lily (1998), "A Book of Life? How the Genome Became an Information System and DNA a Language", Perspectives in Biology and Medicine 41: 504-526.

Keller, Evelyn Fox (1995), Refiguring Life. New York: Columbia University Press.

Levins, Richard (1968), Evolution in Changing Environments. Princeton: Princeton University Press.

Lewontin, Richard (1993), Biology as Ideology. New York: HarperPerennial.

Maynard Smith, John (1975), The Theory of Evolution, 3rd ed. Middlesex: Penguin. (1986), The Problems of Biology. New York: Oxford University Press. 
Maynard Smith, John and Eörs Szathmáry (1995), The Major Transitions in Evolution. Oxford: W. H. Freeman.

Morowitz, Harold, Bettina Heinz, and David Deamer (1988), "The Chemical Logic of a Minimum Protocell", Origins of Life \& Evolution of the Biosphere 18: 281-287.

Moss, Lenny (1992), "A Kernel of Truth? On the Reality of the Genetic Program", in David Hull, Mickey Forbes, and Kathleen Okruhlik (eds.), PSA 1992, vol. 1. East Lansing, MI: Philosophy of Science Association, 335-348.

Neumann-Held, Eva (1998), "The Gene is Dead-Long Live the Gene! Conceptualizing Genes the Constructionist Way", in Peter Koslowski (ed.), Sociobiology and Bioeconomics: The Theory of Evolution in Biological and Economic Theory. Berlin: SpringerVerlag, 105-137.

Oyama, Susan (1985), The Ontogeny of Information. New York: Cambridge University Press.

Sarkar, Sahotra (1996), "Biological Information: A Skeptical Look at Some Central Dogmas of Molecular Biology", in Sahotra Sarkar (ed.), The Philosophy and History of Molecular Biology: New Perspectives. Dordrecht: Kluwer Academic Publishers, 187-231.

Sterelny, Kim and Philip Kitcher (1988), "Return of the Gene", Journal of Philosophy 85: 339-361.

Sterelny, Kim, Kelly Smith, and Michael Dickison (1996) "The Extended Replicator", Biology and Philosophy 11: 377-403.

Szathmáry, Eörs and John Maynard Smith (1997), "From Replicators to Reproducers: The First Major Transitions Leading to Life", Journal of Theoretical Biology 187: 555--572.

Wade, Michael and James Griesemer (1998), "Populational Heritability: Empirical Studies of Evolution in Metapopulations," American Naturalist 151: 135-147.

Wimsatt, William (1974), "Complexity and Organization", in Kenneth Schaffner and Robert S. Cohen (eds.) PSA 1972. Boston Studies in Philosophy of Science, 20: 67-86.

. (1980), "Reductionistic Research Strategies and Their Biases in the Units of Selection Controversy", in Thomas Nickles (ed.), Scientific Discovery, volume II: Historical and Scientific Case Studies. Dordrecht: D. Reidel, 213-259. 
http://www.jstor.org

\title{
LINKED CITATIONS \\ - Page 1 of 1 -
}

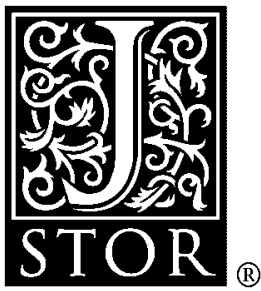

You have printed the following article:

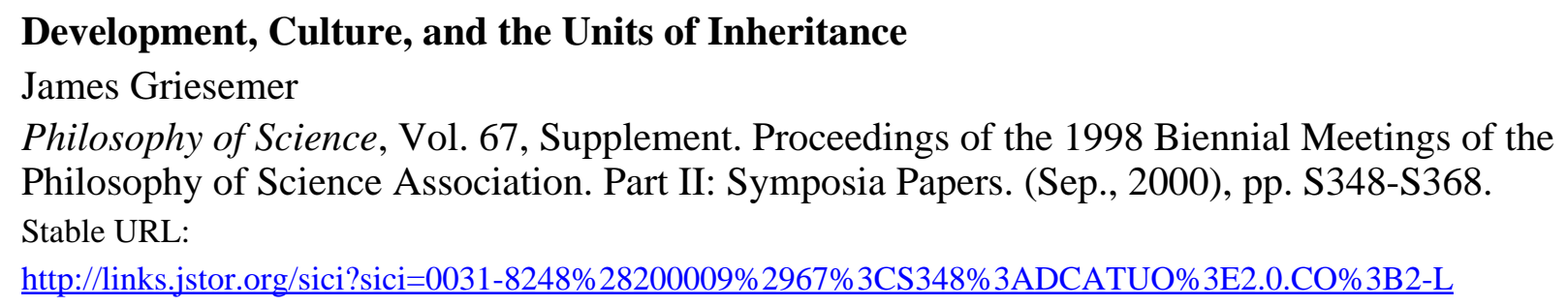

This article references the following linked citations. If you are trying to access articles from an off-campus location, you may be required to first logon via your library web site to access JSTOR. Please visit your library's website or contact a librarian to learn about options for remote access to JSTOR.

\section{References}

\author{
Developmental Systems and Evolutionary Explanation \\ P. E. Griffiths; R. D. Gray \\ The Journal of Philosophy, Vol. 91, No. 6. (Jun., 1994), pp. 277-304. \\ Stable URL: \\ http://links.jstor.org/sici?sici=0022-362X\%28199406\%2991\%3A6\%3C277\%3ADSAEE\%3E2.0.CO\%3B2-\%23
}

\section{The Return of the Gene}

Kim Sterelny; Philip Kitcher

The Journal of Philosophy, Vol. 85, No. 7. (Jul., 1988), pp. 339-361.

Stable URL:

http://links.jstor.org/sici?sici=0022-362X\%28198807\%2985\%3A7\%3C339\%3ATROTG\%3E2.0.CO\%3B2-G

\section{Populational Heritability: Empirical Studies of Evolution in Metapopulations}

Michael J. Wade; James R. Griesemer

The American Naturalist, Vol. 151, No. 2. (Feb., 1998), pp. 135-147.

Stable URL:

http://links.jstor.org/sici?sici=0003-0147\%28199802\%29151\%3A2\%3C135\%3APHESOE\%3E2.0.CO\%3B2-A 